Tropical Journal of Pharmaceutical Research September 2020; 19 (9): 2009-2014

ISSN: $1596-5996$ (print); 1596-9827 (electronic) (C) Pharmacotherapy Group, Faculty of Pharmacy, University of Benin, Benin City, 300001 Nigeria.

\title{
Extended warfarin treatment versus rivaroxaban treatment for first episode of symptomatic unprovoked pulmonary embolism: A prospective cohort study
}

\author{
Jie Pan, Zong Hao, Xiaohong Sun, Hong Gao, Bin Gao* \\ Department of Vascular Surgery, Shanghai Fifth People's Hospital, Fudan University, Shanghai 200240, China
}

*For correspondence: Email: doctorgaobin@163.com; Tel/Fax: +86-21 64308151

Sent for review: 6 February 2020

Revised accepted: 22 August 2020

\begin{abstract}
Purpose: To compare the benefits and risks of extra 6 months of warfarin therapy with those of rivaroxaban treatment in patients with initial unprovoked pulmonary embolism (PE) episode who completed 3- or 6-month of therapy on heparin/vitamin K antagonist standard regime.

Methods: This prospective observational study included 212 patients with follow-up from July 2013 to July 2018. The primary endpoint was symptomatic recurrent venous thromboembolism (VT), composite of non-fatal symptomatic PE or deep vein thrombosis or fatal VT, and major bleeding (non-fatal/fatal) up to 6 months. Secondary endpoints were death not related to PE or major bleeding.

Results: During the 6-month therapy period, the primary endpoint was seen in 3 out of 106 patients $(2.83 \%)$ in warfarin category, and in rivaroxaban category, for a hazard ratio (HR) of 1.22 [95\% confidence interval $(\mathrm{Cl})=0.09-11.18 ; p=0.813$. With warfarin therapy, 2 patients (1.89 \%) had recurrent VT, while 3 patients (2.83\%) had VT with rivaroxaban. Major bleeding was observed in 2 patients $(1.89 \%)$ on warfarin, and in one patient $(0.94 \%)$ on rivaroxaban. During the entire 18-month period, the primary endpoint was seen in 15 patients (14.15\%) treated with warfarin, and in 18 patients $(16.98 \%)$ treated with rivaroxaban (HR 0.84; $95 \% \mathrm{Cl}=0.47-1.84 ; p=0.431$ ). Major bleeding was observed in 5 patients $(4.72 \%)$ under warfarin (one fatal), relative to 3 patients $(2.83 \%)$ under rivaroxaban ( $\mathrm{R}$ 1.67; $95 \% \mathrm{Cl}=0.62-5.95 ; p=0.09)$.

Conclusion: Rivaroxaban showed higher efficacy than warfarin in recurrent VT prevention, with lower risk of major bleeding. However, the extended therapeutic benefit was not maintained post-therapy.
\end{abstract}

Keywords: Pulmonary embolism, Rivaroxaban, Warfarin, Heparin, Vitamin K, Hazard ratio

\begin{abstract}
This is an Open Access article that uses a fund-ing model which does not charge readers or their institutions for access and distributed under the terms of the Creative Commons Attribution License (http://creativecommons.org/licenses/by/4.0) and the Budapest Open Access Initiative (http://www.budapestopenaccessinitiative.org/read), which permit unrestricted use, distribution, and reproduction in any medium, provided the original work is properly credited.

Tropical Journal of Pharmaceutical Research is indexed by Science Citation Index (SciSearch), Scopus, International Pharmaceutical Abstract, Chemical Abstracts, Embase, Index Copernicus, EBSCO, African Index Medicus, JournalSeek, Journal Citation Reports/Science Edition, Directory of Open Access Journals (DOAJ), African Journal Online, Bioline International, Open-J-Gate and Pharmacy Abstracts
\end{abstract}

\section{INTRODUCTION}

Patients with episodes of initial unprovoked venous thromboembolism (VT) have greater recurrence risk when anticoagulant treatment is halted after 3 to 6 months of therapy, relative to patients with VT provoked by risk-factors (e.g., surgery). In such higher risk patients, prolonging anticoagulant therapy past 3 to 6 months is associated with recurrence risk reduction if continuous treatment is provided. However, it is not certain whether such advantage remains constant, since most previous studies did not carry out follow-up of patients after 
discontinuation of therapy [1-5]. Only two studies included patients with initial unprovoked pulmonary embolism (PE), out of studies that evaluated the effect of prolonged duration of anticoagulants for secondary prophylaxis postunprovoked VT. Since the fatality of recurrent VT is about four times greater post-PE than that of deep vein thrombosis (DVT), the risk-benefit ratio of prolonged use of anticoagulants differs in all probability between PE and DVT, and hence should be determined independently $[3,5]$.

Although the incidence of PE in China is unknown, the disorder is gaining greater recognition by the medical services domain in China. This pattern may have emerged because of growing awareness by physicians and the accessibility of minimal/non-invasive diagnostic methods. Records of VT therapy outcomes in Chinese patients are scanty, although there is, by all accounts a general notion that bleeding risk is more in patients on standard therapy, and that treatment with vitamin $\mathrm{K}$ antagonists ought to be dosed cautiously, with a goal of achieving low values of international normalized ratio (INR). Likewise, bleeding concerns are applicable to direct oral anticoagulant therapy.

Rivaroxaban falls under direct Factor $\mathrm{Xa}$ inhibitors with fast onset of action that requires no regular coagulation monitoring. It has minimal interaction with drugs, and it does not interact with food. These desirable properties have been corroborated in a study conducted on Chinese patients [6]. In EINSTEIN DVT and PE studies, rivaroxaban monotherapy was demonstrated to be as efficacious as two-drug treatment involving enoxaparin overlapped with, and accompanied by vitamin $\mathrm{K}$ antagonist, with low incidents of major bleeding $[7,8]$.

The aim of the present study was to conduct a prospective investigation on patients with an initial unprovoked PE episode who were on three- or six-monthly anticoagulant treatment. The purpose was to evaluate the benefits as well as risks of extra 6 months of therapy with warfarin relative to rivaroxaban in patients who completed three or six-months of therapy with heparin/vitamin $\mathrm{K}$ antagonist standard regime. In addition, examination of results for one year after cessation of the studied medications was done.

\section{METHODS}

\section{General information}

This prospective cohort study was carried out in Vascular Surgery Department of Shanghai Fifth People's Hospital. Approval was received from
Institutional Review Board of the hospital (approval no. 2013SP10524), and informed consent was received from participants. Patient confidentiality was strictly maintained. The review was carried out as per the V2008 Helsinki Declaration [9].

\section{Study population}

Patients older than 18 years who were on threeor six-monthly anticoagulants treatment, with an initial unprovoked PE episode, and on extra 6 months of therapy (with either warfarin or rivaroxaban) were included. Unprovoked PE was defined as symptomatic PE which was confirmed objectively, and manifested with no major reversible risk factors for VT within 3 months prior to diagnosis. Other criteria included regional/general anesthesia (>30 min) surgery, trauma with/without lower limb plaster cast, as well as $>72 \mathrm{~h}$ bed rest and no active cancer presence or cancer resolved at least two years before diagnosis.

The exclusion criterion included patients with provoked PE, proximal/distal DVT, recurrent VT or bleeding while on initial anticoagulant therapy, major thrombophilia, vitamin $\mathrm{K}$ antagonist indication for other reasons, and raised bleeding risk. Moreover, patients with serious kidney, cardiovascular, liver, lung, and brain disorders, as well as those who were pregnant, breastfeeding, or planning pregnancy, were excluded. Treatment selection depended on physician and patient's choice of either warfarin or rivaroxaban.

\section{Endpoints}

The primary endpoint was symptomatic recurrent VT (composite of non-fatal symptomatic PE or DVT or fatal VT) and major bleeding (nonfatal/fatal) up to 6 months. The secondary endpoints were death not related to $P E$ and major bleeding during the 6-month therapy period and 18-month study period. The decision of the composite endpoints to assess depended on the outcomes of studies demonstrating recurrent VT, as well as incidence of major bleeding fatality $[3,10]$. Symptomatic recurrent DVT or PE was confirmed using spiral computerized tomographic angiography, ultrasonography, pulmonary angiography, or ventilation-perfusion lung scanning. Bleeding was deemed major when it was fatal, or had critical organ involvement, or overt and in association with decreased hemoglobin level of $\geq 2 \mathrm{~g} / \mathrm{dL}$, or required transfusion with a minimum of 2 units of packed red blood cells. 


\section{Statistical analysis}

Values for categorical variables are expressed as numbers with percentages, while results for continuous variables are expressed as mean \pm standard deviation (SD). Analysis of all data collected was done using SPSS version 21.0 (SPSS Inc, Chicago). Student's $t$-test was used for analysis of continuous variables, and nonparametric tests were utilized for comparison of group differences. An estimate of $p<0.05$ was selected for statistical significance. Kaplan-Meier method was utilized for estimating time-to-event outcomes, while log rank test was utilized for between-group comparisons. Cox regression was utilized for the hazard ratio comparisons with reference standard warfarin.

\section{RESULTS}

Between July 2013 and July 2018, 212 patients were selected in the present study. Six-month extended rivaroxaban therapy was given to 106 patients, while the other 106 patients received 6- month extended warfarin therapy. The clinical and demographic characteristics of the included patients were well balanced at baseline, the exception being that more women and patients with body mass index (BMI) greater than 29 received warfarin (Table 1 ).

During the 6-month therapy period, the primary endpoint was observed in 3 of 106 patients (2.83 $\%$ ) in the warfarin category as well as in the rivaroxaban category, for a hazard ratio $(\mathrm{HR})$ of $1.22(95 \% \mathrm{Cl}=0.09-11.18 ; p=0.813)($ Table $2)$. In the warfarin category, 2 patients $(1.89 \%)$ had recurrent VT, which were unprovoked and presented post-discontinuation of warfarin. In the rivaroxaban category, 3 patients $(2.83 \%)$ had unprovoked recurrent VT. Major bleeding was observed in 2 patients $(1.89 \%)$ in the warfarin category (one with retroperitoneal bleeding, and the other with epistaxis). In the rivaroxaban category, one patient $(0.94 \%)$ had major bleeding. However, these events were non-fatal (Table 2).

Table 1: Clinical/demographic characteristics of patients

\begin{tabular}{|c|c|c|}
\hline Characteristic & Warfarin $(n=106)$ & Rivaroxaban $(n=106)$ \\
\hline Age (years) ${ }^{*}$ & $61.23 \pm 16.14$ & $59.54 \pm 17.92$ \\
\hline$>65$ years, $\mathrm{n}(\%)$ & $38(35.85 \%)$ & $36(33.96 \%)$ \\
\hline Female, $\mathrm{n}(\%)$ & $63(59.43 \%)$ & $43(40.57 \%)$ \\
\hline Body mass index $\left(\mathrm{BMI} ; \mathrm{kg} / \mathrm{m}^{2}\right)^{*}$ & $28.2 \pm 4.4$ & $28.7 \pm 4.1$ \\
\hline $\mathrm{BMI} \geq 30, \mathrm{n}(\%)$ & $34(32.08 \%)$ & $24(22.64 \%)$ \\
\hline \multicolumn{3}{|l|}{ Comorbid conditions } \\
\hline Chronic heart failure & $3(2.83 \%)$ & $4(3.77 \%)$ \\
\hline Prior cancer & $5(4.72 \%)$ & $3(2.83 \%)$ \\
\hline Chronic respiratory failure & $22(20.75 \%)$ & $20(18.87 \%)$ \\
\hline Prior distal DVT & $12(11.32 \%)$ & $11(10.38 \%)$ \\
\hline \multicolumn{3}{|l|}{ Creatinine clearance, $\mathrm{n}(\%)$} \\
\hline$<30 \mathrm{~mL} / \mathrm{min}$ & 0 & 0 \\
\hline$\geq 30$ to $<50 \mathrm{~mL} / \mathrm{min}$ & $11(10.38 \%)$ & $10(9.43 \%)$ \\
\hline$\geq 50 \mathrm{~mL} / \mathrm{min}$ & $95(89.62 \%)$ & $96(90.57 \%)$ \\
\hline \multicolumn{3}{|l|}{ Diagnostic method, n (\%) } \\
\hline Ventilation perfusion lung scanning & $26(24.53 \%)$ & $27(25.47 \%)$ \\
\hline Spiral computed tomography & $77(72.64 \%)$ & $76(71.69 \%)$ \\
\hline Pulmonary angiography & $3(2.83 \%)$ & $3(2.83 \%)$ \\
\hline \multicolumn{3}{|l|}{ PE characteristics } \\
\hline Residual DVT, n (\%) & $16(15.09 \%)$ & $19(17.92 \%)$ \\
\hline Perfusion defect ( $\geq 10 \%), \mathrm{n}(\%)$ & $36(33.96 \%)$ & $33(31.13 \%)$ \\
\hline D-dimer level ( $\mathrm{ng} / \mathrm{mL})$ & $376.4 \pm 559.3$ & $352.1 \pm 483.4$ \\
\hline Systolic pulmonary arterial pressure, $\mathrm{mmHg}$ & $31.2 \pm 7.1$ & $30.8 \pm 8.0$ \\
\hline \multicolumn{3}{|l|}{ Thrombophilia, n (\%) } \\
\hline Major & $5(4.72 \%)$ & $6(5.66 \%)$ \\
\hline Minor & $29(27.36 \%)$ & $25(23.58 \%)$ \\
\hline Compression stockings usage, $\mathrm{n}(\%)$ & $61(57.55 \%)$ & $64(60.38 \%)$ \\
\hline \multicolumn{3}{|l|}{ Major concomitant treatments, $\mathrm{n}(\%)$} \\
\hline Statins & $22(20.75 \%)$ & $20(18.87 \%)$ \\
\hline Antiplatelet agents & $11(10.38 \%)$ & $8(7.55 \%)$ \\
\hline \multicolumn{3}{|l|}{ Bleeding risk, $\mathrm{n}(\%)$} \\
\hline Low & $25(23.58 \%)$ & $29(27.36 \%)$ \\
\hline Moderate & $36(33.96 \%)$ & $39(36.79 \%)$ \\
\hline High & $46(43.39 \%)$ & $43(40.57 \%)$ \\
\hline
\end{tabular}


Table 2: Primary and secondary endpoints

\begin{tabular}{|c|c|c|c|c|}
\hline Characteristic & $\begin{array}{c}\text { Warfarin }(n= \\
106)\end{array}$ & $\begin{array}{c}\text { Rivaroxaban ( } \mathrm{n} \\
=106)\end{array}$ & Hazard Ratio $(\mathrm{Cl})$ & $P$-value \\
\hline \multicolumn{5}{|l|}{ During 6-month therapy period } \\
\hline Primary endpoint & $3(2.83 \%)$ & $3(2.83 \%)$ & $1.22(0.09-11.18)$ & 0.813 \\
\hline Recurrent VT & $2(1.89 \%)$ & $3(2.83 \%)$ & $0.81(0.49-1.63)$ & 0.344 \\
\hline Nonfatal symptomatic PE & 1 & 2 & & \\
\hline Nonfatal symptomatic DVT & 1 & 1 & & \\
\hline Fatal PE & 0 & 0 & & \\
\hline Major bleeding & $2(1.89 \%)$ & $1(0.94 \%)$ & $2.18(0.41-4.84)$ & 0.04 \\
\hline Nonfatal & 2 & 1 & & \\
\hline Fatal & 0 & 0 & & \\
\hline Death from other causes & $1(0.94 \%)$ & $1(0.94 \%)$ & $1.19(0.34-9.61)$ & 0.336 \\
\hline \multicolumn{5}{|l|}{ During 18 -month entire period } \\
\hline Primary endpoint & $15(14.15 \%)$ & $18(16.98 \%)$ & $0.84(0.47-1.84)$ & 0.431 \\
\hline Recurrent VT & $12(11.32 \%)$ & $15(14.15 \%)$ & $0.79(0.28-2.14)$ & 0.626 \\
\hline Nonfatal symptomatic PE & 8 & 13 & & \\
\hline Nonfatal symptomatic DVT & 2 & 2 & & \\
\hline Fatal PE & 2 & 1 & & \\
\hline Major bleeding & $5(4.72 \%)$ & $3(2.83 \%)$ & $1.67(0.62-5.95)$ & 0.09 \\
\hline Nonfatal & 4 & 3 & & \\
\hline Fatal & 1 & 0 & & \\
\hline Death from other causes & $4(3.77 \%)$ & $3(2.83 \%)$ & $1.26(0.11-5.88)$ & 0.148 \\
\hline
\end{tabular}

In the follow-up post-therapy, the primary endpoint was seen in 12 patients who took warfarin (11.32 \%), and in 15 patients who received rivaroxaban $(14.15 \%)$. In the warfarin category, 10 patients $(9.43 \%)$ had recurrent VT, all with no anticoagulants, and there were 6 unprovoked events $(60 \%)$ and 2 fatal events. In the rivaroxaban category, 13 patients $(12.26 \%)$ had recurrent VT, all with no anticoagulants, and there were 9 unprovoked events $(69.23 \%)$ and 1 fatal event. Major bleeding was observed in 2 patients $(1.89 \%)$ in the warfarin category (one fatal and another non-fatal), whereas one patient $(0.94 \%)$ had major bleeding in the rivaroxaban category (non-fatal), for a HR of $2.18(95 \% \mathrm{Cl}=$ $0.41-4.84 ; p=0.04$ ).

On the whole, the primary composite endpoint was seen in 15 patients $(14.15 \%)$ on warfarin treatment, and in 18 patients (16.98\%) on rivaroxaban therapy, with a $\mathrm{HR}$ of $0.84(95 \% \mathrm{Cl}=$ 0.47 - 1.84; $p=0.431$ ). Major bleeding was observed in 5 patients $(4.72 \%)$ in the warfarin category (one fatal) when compared to 3 patients $(2.83 \%)$ in the rivaroxaban category (non-fatal), for a HR of $1.67(95 \% \mathrm{Cl}=0.62-5.95 ; p=0.09)$.

\section{DISCUSSION}

In present study involving patients with an initial unprovoked PE episode who were given extra 6 months of therapy with either warfarin or rivaroxaban, there was no significant difference in the composite primary endpoint, but a significantly lower percentage of major bleeding was found in the rivaroxaban group. However, this benefit of extended therapy was not seen post-therapy.

Consistent with prior studies that assessed significantly extended anticoagulant therapy for initial unprovoked VT or PE episode, greater percentage recurrent VT was seen in warfarin and rivaroxaban treatment categories [3-5,1113].The relative benefit in terms of efficacy and safety of rivaroxaban compared to warfarin in present study is in line with results of other global studies $[7,8]$.

The treatment guideline utilized in China is similar to the standard treatment utilized in the EINSTEIN studies, i.e., heparins overlapped with, and accompanied by adjusted vitamin $\mathrm{K}$ antagonist treatment $[7,8]$. Previous studies have shown that when patients suffer recurrent VT episode, it normally took a form similar to the initial event $[3-5,10]$. Such situation was seen in present study too. Notwithstanding whether patients were under warfarin or rivaroxaban, nearly $80 \%$ of recurrent VT episodes constituted another symptomatic PE episode. Moreover, the greater number of recurrent VT episodes in both study categories were unprovoked $(>80 \%)$, as seen in other studies [3-5]. Thus, prolonging anticoagulant therapy to 6 months had no effect on the clinical manifestation of recurrent VT. Most recurrent VT episodes were nonpreventable and amounted to the most serious type of VT. 
The present study outcome recommends that patients have need for long-term maintenance measures. However, the incorporation of precise therapies with new anticoagulants, vitamin $\mathrm{K}$ antagonists, or aspirin, or therapies customized as per risk factors (including raised D-dimer levels) of patients requires further investigations.

\section{Limitations of the study}

Certain intrinsic limitations should be considered while interpreting the outcomes of this study. Being a one-center study with very limited number of patients, one should be cautious in generalizing the results. The primary endpoint constituted two distinctive result estimates that might not be equivalent clinically, though each has comparable and high fatality rate $[3,14]$.

\section{CONCLUSION}

In patients with an initial unprovoked PE episode who received extra 6 months of warfarin or rivaroxaban therapy, rivaroxaban showed more efficacy than warfarin in recurrent VT prevention, with lower major bleeding risk. However, this benefit of extended therapy was not maintained post-therapy.

\section{DECLARATIONS}

\section{Acknowledgement}

The project was funded by the Medical System Discipline Construction Project of Minhang District, Shanghai, China (no. 2017MWDXK01).

\section{Conflict of interest}

No conflict of interest is associated with this work.

\section{Contribution of authors}

We declare that this work was done by the authors named in this article and all liabilities pertaining to claims relating to the content of this article will be borne by the authors.

\section{Open Access}

This is an Open Access article that uses a funding model which does not charge readers or their institutions for access and distributed under the terms of the Creative Commons Attribution License (http://creativecommons.org/licenses/by/ 4.0) and the Budapest Open Access Initiative (http://www.budapestopenaccessinitiative.org/rea d), which permit unrestricted use, distribution, and reproduction in any medium, provided the original work is properly credited.

\section{REFERENCES}

1. Kearon C, Akl EA, Comerota AJ, Prandoni $P$, Bounameaux H, Goldhaber SZ, Nelson ME, Wells PS, Gould MK, Dentali F, et al. Antithrombotic therapy for VTE disease: Antithrombotic Therapy and Prevention of Thrombosis, 9th ed: American College of Chest Physicians Evidence-Based Clinical Practice Guidelines [published correction in Chest 2012;142(6):1698-1704]. Chest 2012; 141(2 suppl): e419S-494S.

2. Konstantinides SV, Torbicki A, Agnelli G, Danchin N, Fitzmaurice $D$, Galiè N, Gibbs JSR, Huisman MV, Humbert M, Kucher N, et al. 2014 ESC guidelines on the diagnosis and management of acute pulmonary embolism. Eur Heart J 2014; 35(43): 3033-3069, 3069a3069k.

3. Couturaud F, Sanchez $O$, Pernod G, Mismetti $P$, Jego $P$, Duhamel E, Provost $K$, Sollier CB, Presles E, Castellant $P$, et al. Six months vs extended oral anticoagulation after a first episode of pulmonary embolism: the PADISPE randomized clinical trial. JAMA 2015; 314(1): 31-40.

4. Agnelli $G$, Prandoni $P$, Santamaria $M G$, Bagatella $P$, Iorio A, Bazzan M, Moia M, Guazzaloca G, Bertoldi A, Tomasi $C$, et al. Three months versus one year of oral anticoagulant therapy for idiopathic deep venous thrombosis. Warfarin Optimal Duration Italian Trial Investigators. N Engl J Med 2001; 345(3): 165-169.

5. Agnelli $G$, Prandoni $P$, Becattini $C$, Silingardi $M$, Taliani MR, Miccio M, Imberti D, Poggio R, Ageno W, Pogliani $E$, et al. Extended oral anticoagulant therapy after a first episode of pulmonary embolism. Ann Intern Med 2003; 139(1): 19-25.

6. Jiang J, Hu Y, Zhang J, Yang J, Mueck W, Kubitza D, Bauer RJ, Meng L, Hu P. Safety, pharmacokinetics and pharmacodynamics of single doses of rivaroxaban - an oral, direct factor Xa inhibitor - in elderly Chinese subjects. Thromb Haemost 2010; 103(1): 234-241.

7. The EINSTEIN Investigators. Oral rivaroxaban for symptomatic venous thromboembolism. N Engl J Med 2010; 363: 2499-2510.

8. The EINSTEIN-PE Investigators. Oral rivaroxaban for the treatment of symptomatic pulmonary embolism. $N$ Engl J Med 2012; 366: 1287-1297.

9. World Medical Association. Declaration of Helsinki, Ethical Principles for Medical Research involving human subjects. Available from: http:// https://www.wma.net/wpcontent/uploads/2016/11/DoH-Oct2008.pdf. [last accessed on 2019 Aug 22]

10. Lecumberri $R$, Alfonso A, Jiménez $D$, Capitán $C F$, Prandoni P, Wells PS, Vidal G, Barillari G, Monreal M, RIETE investigators. Dynamics of case-fatality rates of recurrent thromboembolism and major bleeding in patients treated for venous thromboembolism. Thromb Haemost 2013; 110(4): 834-843.

Trop J Pharm Res, September 2020; 19(9): 2013 
11. Schulman S, Kearon C, Kakkar AK, Schellong S, Eriksson $H$, Baanstra $D$, Kvamme AM, Friedman J, Mismetti $P$, Goldhaberet SZ, et al. Extended use of dabigatran, warfarin, or placebo in venous thromboembolism. N Engl J Med 2013; 368(8): 709-718.

12. EINSTEIN Investigators, Bauersachs $R$, Berkowitz $S D$, Brenner B, Buller HR, Decousus H, Gallus AS, Lensing AW, Misselwitz $F$, Prins $M H$, et al. Oral rivaroxaban for symptomatic venous thromboembolism. $N$ Engl $\mathrm{J}$ Med 2010; 363(26): 2499-2510.
13. Agnelli G, Buller HR, Cohen A, Curto M, Gallus AS, Johnson M, Porcari A, Raskob GE, Weitz JI, AMPLIFYEXT Investigators, et al. Apixaban for extended treatment of venous thromboembolism. N Engl J Med 2013; 368 (8): 699-708.

14. Linkins LA, Choi PT, Douketis JD. Clinical impact of bleeding in patients taking oral anticoagulant therapy for venous thromboembolism: a meta-analysis. Ann Intern Med 2003; 139(11): 893-900. 